\title{
Bottlenecks in material cycle of nickel
}

\author{
Kenichi Nakajima ${ }^{1, a}$, Ichiro Daigo ${ }^{2}$, Kenichi Okada ${ }^{3}$, Shimpei Koike ${ }^{3}$, \\ Keisuke Nansai ${ }^{1}$, Kazuyo Matsubae ${ }^{4}$, Osamu Takeda ${ }^{5}$ and Takahiro Miki ${ }^{5}$
}

Received 19 September 2016, Accepted 20 February 2017

\begin{abstract}
Economic growth is associated with a rapid rise in the use of natural resources, and has potential environmental impacts at local and/or global scales. Possible options to control environmental impacts associated with consumption of natural resources include the introduction of easier way to identify the consumption of natural resources and the associated environmental impacts through the global supply chain, and the establishment of sound material cycle to reduce the consumption of national resources. Nickel and nickel-containing materials, whose global demand has risen rapidly in recent years, play a crucial role in modern society, with uses in numerous types of infrastructure and technology. At the same time, the life cycles of nickel-containing materials are always associated with environmental risks and challenges (Nakajima et al. 2014). Especially, the environmental impacts caused by nickel mining has received particular attention in recent years, because the world's leading countries and regions of nickel ore production (e.g., New Caledonia, Philippines and the Republic of Indonesia) are also typically known as biodiversity hotspots (Myers et al. 2000). However, we can see material and/or quality losses of nickel throughout anthropogenic nickel cycle (Reck and Graedel 2012). Possible options to reduce the environmental impacts associated with nickel mining include nickel recovery from wastes such as spent batteries and catalysts, plating sewage, and industrial water. Recovery of these wastes has a potential to reduce natural resource consumption, and to reduce a negative impact on the environment and human health if they contaminate soil, water, and air. In this study, we discussed a bottleneck for establishing sound material cycle of nickel. Hence, upon assessing the generation and processing of nickel-containing wastes, we clarify the quality of nickel-containing waste, as well as the technical bottlenecks for closing the loop on the material cycle of nickel. Sound material cycle of nickel-containing steel scrap has been established in Japan; with reports of almost of nickel-based stainless scrap being recycled (Daigo et al. 2010). Therefore, this study addressed nickel-containing waste that are of particular concern for losses, such as pre-consumer materials with low-grade nickel content. This study identified characteristics of nickel containing pre-consumer materials generated from steel production industry (stainless steel), electrodepositing tool production industry, edible oils and fats industry, and nickel plating industry.
\end{abstract}

Key words: Nickel / recycle / waste management / loss / material cycle

\section{Introduction}

The supply and demand situation for resources continues to change rapidly owing to factors including the economic development of emerging nations and tech- nological innovation in industrialized nations. Demand for mineral resources and metals that has increased with the economic development of industrialized nations is forecasted [1] to further expand with the recent economic development of emerging nations. At the same time, it has

\footnotetext{
a Corresponding author: nakajima.kenichi@nies.go.jp

1 Center for Material Cycles and Waste Management Research, National Institute for Environmental Studies, 16-2 Onogawa, Tsukuba, Ibaraki, 305-8506, Japan

2 Department of Materials Engineering, Graduate School of Engineering, The University of Tokyo, 7-3-1 Hongo, Bunkyo-ku, Tokyo, 113-8656, Japan

3 AMITA CORPORATION, Mujinayama-1-3 Harachō, Toyohashi-shi Aicgi-ken 441-3133, Japan

4 Department of Environmental Studies for Advanced Society, Graduate School of Environmental Studies, Tohoku University, Miyagi 980-8579, Japan

5 Department of Metallurgy, Materials Science and Materials Processing, Graduate School of Engineering, Tohoku University, 6-6-2 Aoba, Aramaki, Aoba-ku, Sendai, Miyagi 980-8579, Japan
} 
been noted that demand for resources will change and increase along with measures such as the deployment of low-carbon technologies by industrialized nations [2]. Furthermore, growth in resource use has been accompanied by deterioration of the global environment and the need for sustainable management of resources has become urgent. In discussions by the UNEP (United Nations Environment Programme) International Resource Panel, the importance of sustainable metal management and recycling required for this purpose [3]. In addition, discussions regarding the Circular Economy Strategy [4] have become active in Europe, with closing the loop of material cycles and economic stimulation accompanying resource renewal attracting attention.

In this study, we used nickel $(\mathrm{Ni})$ as an example of a material whose demand is rapidly growing with global economic development [5] to examine the bottlenecks to closing the loop for the material cycle of nickel. Materials that contain nickel are becoming increasingly useful from the standpoint of physical and other properties; however, the demand for nickel has grown rapidly as with other metal resources, and there have been reports of global environmental problems accompanying its extraction and refining [6]. In addition to past reports of impacts including loss of animal and plant habitat accompanying extraction and refining [7] and on biodiversity [8], there have been case reports from nickel ore- and ferronickel/nickel metal-producing countries of encroachment on nature protection zones [9]; inappropriate environmental management at production facilities accompanied by heavy metal pollution [10,11]; and emissions including sulfur oxides and mining waste [12]. In addition, estimates have been reported of the large amounts of (1) energy involved and (2) greenhouse gases emitted in accompaniment with reduction and other processes in producing substances such as ferronickel $[13,14]$. Reck and Graedel [15] have noted that in the anthropogenic cycle for nickel, about $48 \%$ of the nickel extracted worldwide is lost during the life cycle for nickel. Thus, avoiding the loss of nickel in its anthropogenic cycle and closing the loop for the material cycle of nickel would be expected to reduce the consumption of natural resources and contribute to the reduction of environmental impacts.

In this study, we discuss issues for the material cycle of nickel in Japan, which is home to a steel industry where nickel is mainly used to produce stainless steel, as well as world leading nickel-refining and ferronickelrefining industries. In Japan, conventional nickel-refining and ferronickel-refining have been optimized for economical and efficient extraction of desired elements from large amount of raw materials originated from primary resources under constant grade, and elements not contained in natural resources have not been sufficiently controlled. Hence, upon assessing the generation and processing of nickel-containing wastes, we clarify the quality of nickelcontaining waste, as well as the technical bottlenecks for closing the loop on the material cycle of nickel. Sound material cycle of nickel-containing steel scrap has been established in Japan; with reports of almost of nickel-based stainless scrap being recycled [16]. Therefore, this study addressed nickel-containing waste that are of particular concern for losses, such as pre-consumer materials with low-grade nickel content.

\section{Method and data}

A survey of manufacturing industries was conducted for Japanese fiscal year 2014, and the generation of pre-consumer materials with low concentration of nickel, amount of material processed offsite (waste management or sales), and processing methods including recycling were investigated. The fiscal year in Japan begins on April 1st. So fiscal year 2014 begun on 1 April 2014 and ended on 31 March 2015. Here, waste management is defined as processing that accompanies the payment of processing fees to the waste management industry. For generated materials containing nickel (or assumed to contain nickel), the following types of materials were investigated: (1) materials containing less than 5 wet\% nickel (nickel content of total material including water) and (2) materials that could not be recycled regardless of the nickel content. Manufacturing industries surveyed included the stainless steel production industry, diamond tool and other electrodepositing tool production industries, and the edible oils and fats production industry. In addition, other cooperating industries were separately surveyed. The generated amount of waste, including nickel plating sludge, was examined in a study conducted in fiscal year 2004 by the Ministry of Economy, Trade, and Industry, which showed that 1200 tons of nickel were generated and that this waste was almost totally landfilled [17]. Given that a study by the authors and others in fiscal year 2013 also reported similar trends [18], these wastes were not included in the present survey. The production industries surveyed in our investigation were not included in the fiscal year 2004 study [17].

Investigation of the stainless steel production industry assumed the generation of acid washed sludge and other wastes. We obtained the cooperation of the Japan Stainless Steel Association in investigating the 7 main stainless steel production companies of Japan. The Japan Stainless Steel Association reports that the 7 companies account for $39.9 \%$ of Japan's stainless steel production, and this was used as the share of the investigated companies. All of the questionnaires were returned (100\% response rate).

For investigating the electrodepositing tool production industry, in which nickel is used in the electrodeposition process of diamond production, we assumed the generation of nickel-containing sludge, and other wastes. We surveyed 90 facilities of 45 member companies belonging to the Industrial Diamond Association of Japan. The Industrial Diamond Association reports that these companies account for $65 \%$ of the production by association members, and this was used as the share of the investigated companies. The response rate was $30 \%$. For reference purposes, 8 non-member companies (18 facilities) were surveyed and $16.7 \%$ of the questionnaires were returned. 
For the edible oils and fats industry, the disposal of used nickel-containing catalysts was assumed. In the edible oils and fats industry, nickel catalysts are used to hydrogenate unsaturated fatty acids in oils and fats when producing edible processed oils and fats from natural oils (such as soybean oil and rape seed oil). We surveyed 44 member companies (149 facilities) of the Japan Oilseeds Processors Association and the Japan Margarine, Shortening, and Lard Industries Association, and $29.5 \%$ of the questionnaires were returned.

Overall, we received responses from 119 facilities including 4 facilities in other production industries (automobile parts production, electronic parts production, semiconductor production). For generation of preconsumer materials containing low concentration of nickel, 35 facilities generated such pre-consumer materials, 71 facilities did not, 1 facility was unsure, and 11 facilities did not enter a response. For offsite processing of the pre-consumer materials, 54 items in total were obtained from the 35 facilities with confirmed the generation of pre-consumer materials. For 49 of the pre-consumer materials, information on their handling (waste management or sales) was also obtained. Of these items, 34 were handled by waste management and 15 items were sold. Fifty responses (waste management: 39, sales: 11 ) were received on the details of processing methods (incineration, landfill, neutralization, recycling, export, or other). With regard to the breakdown of processing methods, the number of responses did not match the number of pre-consumer materials because there were responses that did not disclose information and multiple responses for a single item.

\section{Results}

The results of the survey for pre-consumer materials containing low concentration of nickel showed that a total 46000 tons of such products generated by the stainless steel production, electrodepositing tool production, and edible oils and fats industries, which were processed offsite, had a nickel content of 569 tons (Tab. 1). These results do not include data from the non-member companies of the Industrial Diamond Association and other industries. From the market shares and response rates for the questionnaires, it was estimated that the total nickel content of processed materials from these industries was 1466 tons (stainless steel production industry: 1355 tons; electrodepositing tool production industry: 42 tons; edible oils and fats industry: 69 tons). However, as market share data for the edible oils and fats industry was not obtained, only the questionnaire response rate was used.

Figure 1 shows the frequency distribution of nickel content $\left(\mathrm{C}_{\mathrm{Ni}}\right.$, dry\%) for the 49 processed pre-consumer materials for which responses were obtained on the breakdown of their handling. Overall, the majority of the preconsumer materials had a nickel content of less than 2 dry\%, and most were handled by waste management. The nickel content was not analyzed for 4 of the 34 pre-consumer materials reported to be handled by waste management. Two pre-consumer materials with a nickel content of about 100 dry\% were reported to have been handled by waste management. Each of these items was sludge generated by a wastewater treatment process for the electrodeposition tool industry; each was reportedly handled by a waste management process because it contained phosphorus in addition to a moisture content of greater than $70 \%$. In contrast, of the 15 pre-consumer materials reportedly sold, waste liquid ( $0.1 \mathrm{dry} \%-\mathrm{Ni})$ generated by an aluminum surface treatment process and scale (1.7 dry $\%-\mathrm{Ni}$ and 2.0 dry $\%-\mathrm{Ni}$ ) originating from a steel material rolling process were included. These are examples of the effect that other elements present or their values have on the sale of these materials. It should be noted that recovery of nickel might not have been the objective for some of the pre-consumer materials sold.

Figure 2 shows the detailed breakdown of the handling of pre-consumer materials. For the 39 nickel-containing pre-consumer materials handled by waste management, 21 were managed by non-resource recovery processes (landfill: 8 items, neutralization: 7 items, incineration: 6 items). For these 21 items, the nickel content was known for 17 of the pre-consumer materials processed. Sold items included one for which the objective was neutralization processing. This item was presumably sold for use as a substitute for caustic soda in a neutralization process. In addition to the 9 pre-consumer products sold for recycling, 12 of the items handled by waste management were reportedly recycled. The results of our survey also showed that for Japan, waste management industry partly conducted the recovery of secondary resources from waste stream.

The results of the survey showed that the most frequently reported bottleneck to recycling end-of-life products was deviation from quality standards for nickel or phosphorus content (15 responses). Other issues included lack of information on recycling companies (6 responses) and excessive facility investment (4 responses). Of the responses citing cost, one cited the low cost of landfill disposal.

\section{Discussion}

This study revealed actual losses of nickel through the handing of nickel-containing pre-consumer material. This means that the loop has not been closed for nickel, even in Japan with its leading nickel-refining, ferronickel-refining, and steel industries. Below, we discuss the bottlenecks for achieving closed-loop cycling of nickel from the perspectives of quantity and quality of end-of-life products.

First, for the quantities of pre-consumer materials as secondary resource, we found that the offsite processing of pre-consumer materials per production facility obtained for each industry was 77 tons nickel per production facility for the stainless steel industry, 0.68 tons nickel per production facility for the electrodeposition tool industry, and 2.3 tons nickel per production facility for the edible oils and fats industry. This suggests that the amount of potentially secondary resources, that is the amount of 
K. Nakajima et al.: Matériaux \& Techniques 104, 604 (2016)

Table 1. Amount of pre-consumer materials processed offsite (pre-consumer materials with low concentration of nickel).

\begin{tabular}{ccc}
\hline & Gross weight, 1000 ton & Nickel content, ton \\
\hline Steel production industry (stainless steel) & 42.3 & 541 \\
Electrodepositing tool production industry & 2.1 & 8 \\
Edible oil and fats industry & 1.6 & 20 \\
\hline Total & 46.0 & 569 \\
\hline
\end{tabular}

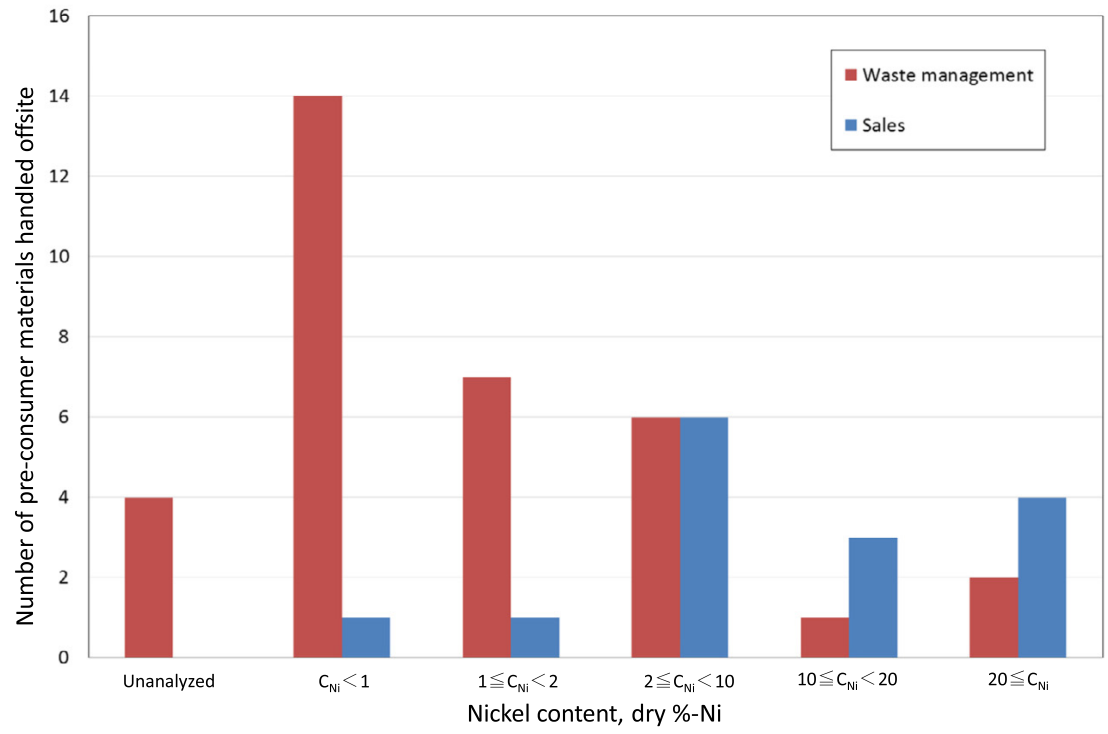

Fig. 1. Number of pre-consumer materials handled offsite and distribution of nickel content.

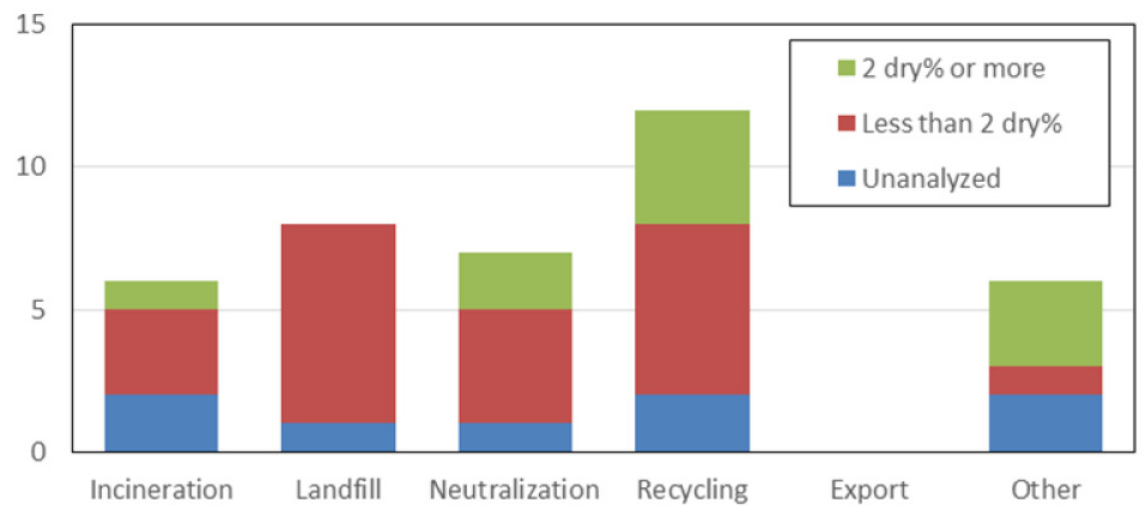

(a) Waste management

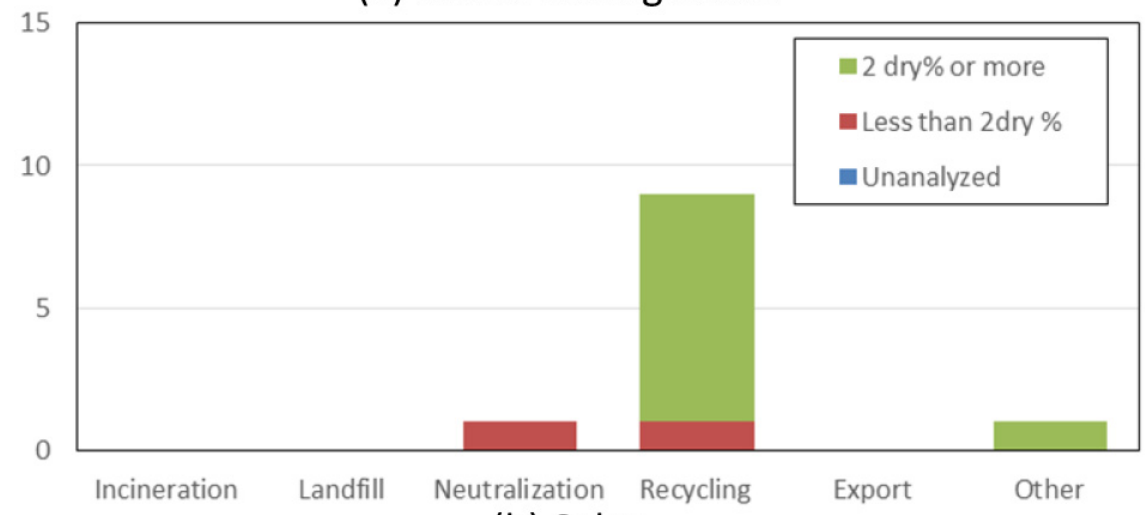

(b) Sales

Fig. 2. Number of pre-consumer materials processed offsite and processing method: (a) waste management, (b) sales. 


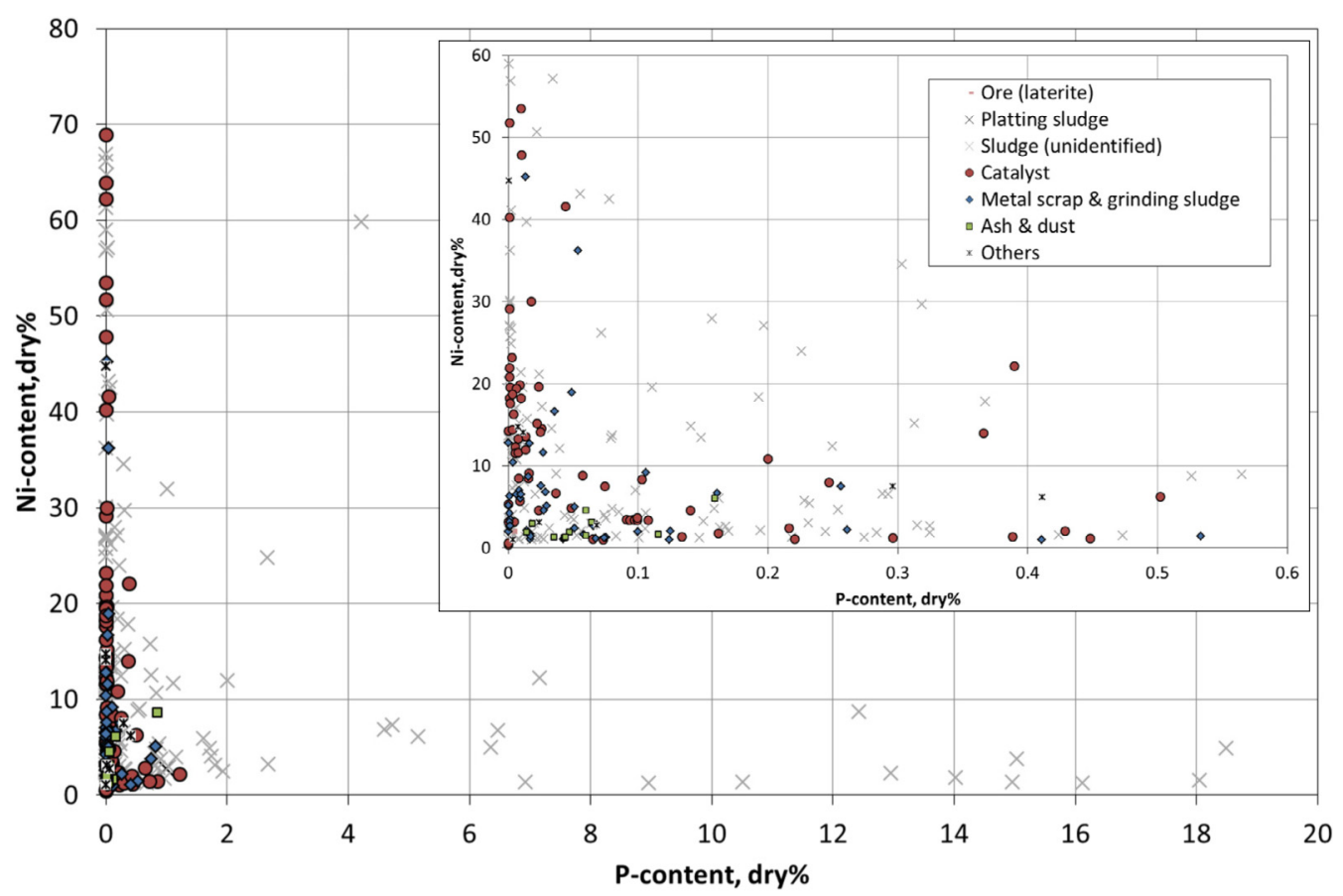

Fig. 3. Nickel and phosphorus content of pre-consumer materials.

pre-consumer materials processed offsite for each production facility, may be quite small. The issue of resource quantity was also shown in previous research to be a bottleneck [18]. To further close the loop for material circulation, measures such as concentrated processing of the pre-consumer materials to supply secondary resources from waste steam can be considered.

Next, we discuss the grades of nickel-containing preconsumer materials and their deviation from the permissible grade of raw materials in the metallurgical industry. Below, we consider the bottlenecks to closing the loop for nickel cycle, including nickel plating waste liquids and sludge, whose potential to become loss were revealed in previous studies. Managing the quality of nickel content and impurities is difficult for these pre-consumer materials. In contrast, the processes for nickel refining and ferronickel production are optimized for economical and efficient extraction of desired elements from large amount of ores and processed materials under constant grade. Hence, managing the grade of secondary resources for use as recycled raw materials is required [17, 18]. For use as raw materials, in addition to nickel content, the levels of common impurities such as phosphorus must be managed [17]. Figure 3 shows the nickel content and phosphorus content for nickel ore (laterite ore) and nickelcontaining pre-consumer materials obtained from the literature $[17,19,20]$, interviews, and sample analyses. These data include samples that have been dewatered or upgraded nickel concentration at the generation source. Compared with the grades of nickel ore used as the main raw materials for ferronickel, plating sludge and used catalysts had nickel contents equivalent to or higher than those of ores. In contrast, plating sludge had much higher levels of phosphorus than did ores. According to refining companies, a nickel content to phosphorus content ratio $(\mathrm{Ni} / \mathrm{P})$ of 100 or greater (in a case; 800 or greater) has been set as the permissible phosphorus level in ferronickel refining, whereas grades such as a nickel content of $30 \%$ or greater and a phosphorus content of less than $0.5 \%$ have apparently been set in nickel refining. Although these standards vary with the market price of nickel, they show that there is a wide gulf between the grades demanded by refining industries and the grades of pre-consumer materials. If the average nickel content $(10.9 \%)$ and average phosphorus content (1.19\%) of the plating sludge shown in Figure 3 are taken as examples, processing to increase the $\mathrm{Ni} / \mathrm{P}$ value 11 -fold ( 88 -fold) would be required to meet the ferronickel refining standard.

In closing, we discuss measures for ameliorating or relaxing the differences between the grades of pre-consumer materials and grade of raw material in metallurgical industry (Fig. 4). In addition to quality management of pre-consumer materials by sources [18], measures such as (a) upgrading the quality of pre-consumer materials by removing impurities, (b) adjusting the quality of preconsumer materials by mixing and diluting, and (c) relaxing the limits on impurities by refineries can be considered to close the loop for nickel cycle. Methods for removing impurities or increasing the concentration of target substances include the use of solvent extraction $[21,22]$ and ion exchange resins [23], sulfur coagulation [24], and dry melting furnaces [25]. In addition, phosphorus removal technology [26] for ferronickel refining would relax the limits on impurities. In recent years, a process control that does not require phosphorus removal has been achieved by using ores and coal for raw materials with low phosphorus levels. However, phosphorus removal technologies are thought to be effective in broadening the range of 


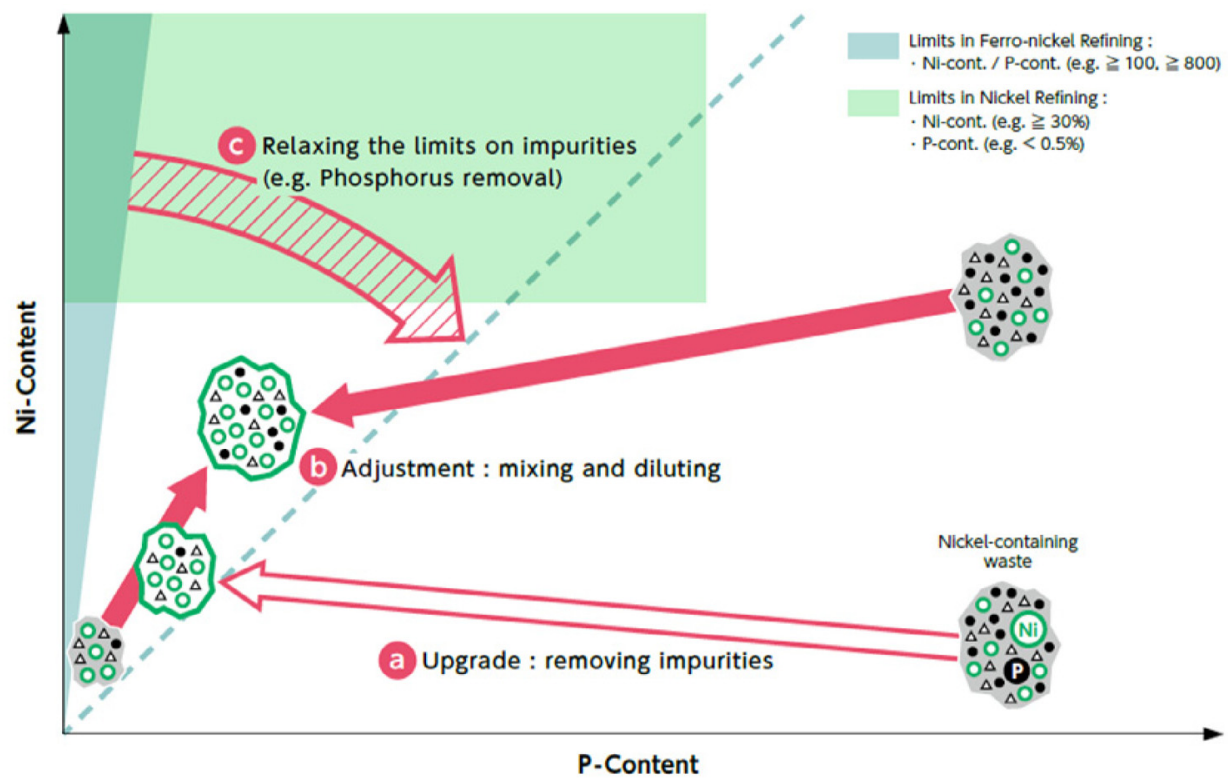

Fig. 4. Measures for ameliorating or relaxing the differences; the grades of pre-consumer materials and grade of raw material in metallurgical industry.

secondary resources that can be used for raw materials. Although the technologies are far from inexpensive, some advanced companies have already adopted the technologies for closing the loop of nickel cycle e.g. [21-26]. For these technologies to be widely adopted, the development of cost-effective technologies will be crucial. It will be necessary to design a system for closing the loop that includes consideration of appropriate pricing of industrial waste management.

Acknowledgements. The authors are grateful to the Japan Stainless Steel Association and the Industrial Diamond Association of Japan for cooperation with the survey. The authors also thank Wataru Takayanagi for drawing the Figure 4. This research was partially supported by the Japan Society for the Promotion of Science (KAKENHI 26281059 and KAKENHI 15H02862) and the Research Institute of Science and Technology for Society of Japan's Science and Technology Agency (JST-RISTEX) as the research program on Science of the Science, Technology and Innovation Policy.

\section{References}

[1] D.P. van Vuuren, B.J. Strengers, H.J.M. De Vries, Resource Policy 25 (1999) 239-255

[2] R. Kleijn, E. van der Voet, G.J. Kramer, L. van Oers, C. van der Giesen, Energy 36 (2011) 5640-5648

[3] United Nations Environment Programme (UNEP), Environmental Risks and Challenges of Anthropogenic Metals Flows and Cycles (2013) http://www.unep.org/ resourcepanel/Portals/24102/PDFs/Environmental_ Challenges_Metals-Full\%20Report.pdf

[4] European Commission, Closing the loop - An EU action plan for the Circular Economy, http://eur-lex.europa. eu/legal- content/EN/TXT/?qid=1453384154337\& uri=CELEX : 52015DC0614, (2015)

[5] G.M. Mudd, Ore Geology Reviews 38 (2010) 9-26

[6] K. Nakajima, Y. Otsuka, Y. Iwatsuki, K. Nansai, H. Yamano, K. Matsubae, S. Murakami, T. Nagasaka, Metall. Res. Technol. 111 (2014) 339-346

[7] L. L'Huillier, T. Jaffré, A. Wulef, Mines et Environment en Nouvelle-Calédonie: les milieu sur substrats ultramafiques et leur restauration, IAC, 2010, pp. 21-35

[8] D. Moran, M. Petersone, F. Verones, Ecological Indicators 60 (2016) 192-201

[9] A.P. Durán, J. Rauch. K.J. Gaston, Biological Conservation 160 (2013) 272-278

[10] T. Norseth, The Science of the Total Environmen 148 (1994) 103-108

[11] K. Bačeva, T. Stafilov, R. Šajn, C. Tănăselia, Journal of Environmental Science and Health, Part A 47 (2012) 645-656

[12] G.A. Crawford, Journal of Geochemical exploration 52 (1995) 267-284

[13] G.M. Mudd, Ore Geology Reviews 38 (2010) 9-26

[14] M.J. Eckelman, Conservation and Recycling 54, (2010) 256-266

[15] B.K. Reck, T.E. Graedel, Science 337 (2012) 690-695

[16] I. Daigo, Y. Matsuno, Y. Adachi, Resources Conservation and Recycling $\mathbf{5 4}$ (2010) 851-863

[17] Manufacturing Industries Bureau , Ministry of Economy, Trade and Industry, Actual conditions survey on plating sludge recycling, in Japanese, 2004

[18] K. Nakajima, S. Mitamura, K. Matsubae, M. Tanaka, Environmental Management 9 (2014) 41-45 
[19] Kyushu Bureau of Economy, Trade and Industry, Ministry of Economy, Trade and Industry, Research survey on system model of recycling of plating sludge, http://www.meti.go.jp/policy/recycle/main/ data/research/h16fy/model16-8.html, (2005)

[20] A. Kaikake, Recent ferronickel smelting operation at HYUGA SMELTING Co., LTD., Journal of MMIJ 123 (2007) 686-688

[21] M.Tanaka, H.Naganawa, S.Watanabe, H.Kumono, J. Surf. Finish. Soc. Jpn. 62 (2011) 554-558

[22] M. Okada, S. Kimura, N. Murayama, J. Shibata, K.Otani, Resources Processing 57 (2010) 109-113
[23] T. Fukuta, J. Surf. Finish. Soc. Jpn. 45 (1994) 860-864

[24] A. Onishi, K. Miyazawa, Journal of Japan Society on Water Environment 37A (2014) 47-51

[25] H. Matsui, K. Matsuo, T. Yamamoto, Electric Furnace Steel 80 (2009) 199-204

[26] F.K. Crundewell, M.S. Moats, V. Ramachandran, T.G. Robinson, W.G. Davenport, Extractive Metallurgy of Nickel, Cobalt and Platinum-Group Metals, Elsevier, The Boulevard, Langford Lane, Kidlington, Oxford OX5 1GB, UK, 2011, pp. 85-86 